\title{
Proposição de uma Nova Metodologia Para ReduÇão do Uso de ACETONitrila UTILIZAda EM ENSAios PaRa DETERMinaÇão dOS Aldeídos Presentes nas Emissões Veiculares
}

\author{
Rodrigo Soares Ferreira ${ }^{1}$, Claudio Adriano Deger ${ }^{1}$, Luiz Carlos Daemme $^{1}$ \\ e Marina Scheiffer Nadolny ${ }^{1}$ \\ ${ }^{1}$ Instituto de Tecnologia para o Desenvolvimento - Institutos Lactec \\ E-mails: rodrigo.ferreira@ lactec.org.br, deger@lactec.org..br, luiz.carlos@ @lactec.org.br, \\ marina.nadolny@lactec.org.br
}

\section{RESUMO}

As emissões provenientes de veículos automotores passaram por mudanças substanciais na última década, devido principalmente às mudanças de tecnologias e controle dos motores, motivadas pela redução dos limites de emissão de poluentes. No Brasil, as emissões de aldeídos em veículos abastecidos com gasolina e etanol, focadas em Formaldeído e Acetaldeído, são determinadas de acordo com o procedimento descrito na norma ABNT NBR 12026, que preconiza a utilização de $100 \mathrm{~mL}$ de acetonitrila em cada fase do teste em dinamômetro de chassis. Esta pesquisa teve como objetivo apresentar a proposição de uma nova metodologia para preparo das amostras e posterior quantificação dos aldeídos em emissões veiculares, baseada em princípios de medições gravimétricas, dispensando o processo atual de avolumar as amostras para um volume conhecido. Por meio de pesagem da solução absorvente de 2,4-Dinitrofenilhidrazina em acetonitrila após o teste, é possível determinar com precisão seu volume, pela relação de densidade do solvente. Este procedimento elimina a etapa de aferição do balão volumétrico com acetonitrila, até o volume final de $100 \mathrm{~mL}$. Assim, após a análise cromatográfica das fases do ensaio de emissões, é possível correlacionar às concentrações de formaldeído e acetaldeído presentes no volume determinado por gravimetria. Os resultados obtidos por meio da técnica proposta, em testes realizados tanto em veículos quanto em motocicletas, apresentaram resultados satisfatórios quando comparados com a metodologia tradicional. Deste modo, esta pesquisa mostrou que o procedimento proposto apresenta como benefício principal, a redução aproximada de $40 \%$ do volume utilizado de acetonitrila nos testes, reduzindo o custo e minimizando o descarte de resíduos químicos ao meio ambiente.

\section{INTRODUÇÃO}

Atualmente existe uma grande preocupação em relação às emissões atmosféricas de produtos provenientes da queima de combustíveis em motores. Neste contexto, os veículos automotores contribuem com uma grande parcela destas emissões, principalmente nos grandes centros urbanos, onde, muitas vezes, existe uma carência de políticas públicas ou incentivos para a criação de sistemas de transporte coletivo para a população. Este fato, aliado à grande oferta de veículos e condições favoráveis para aquisição, contribuíram para o aumento considerável da frota nacional, nas últimas décadas. O Programa de Controle de 
Poluição do Ar por Veículos Automotores - PROCONVE, o qual é coordenado pelo IBAMA, surgiu em 6 de maio de 1986 por meio da Resolução CONAMA n ${ }^{\circ} 18$; com a missão de definir os primeiros limites de emissão para veículos leves e contribuir para o atendimento aos Padrões de Qualidade do Ar instituídos pelo Programa Nacional de Controle da Qualidade do Ar (PRONAR) [1].

Na sequência, em 28 de outubro de 1993, a lei $n^{0} 8.723$ endossou a obrigatoriedade de redução dos níveis de emissão dos poluentes de origem veicular. O cumprimento destas exigências é aferido por meio de ensaios padronizados em dinamômetro e com "combustíveis de referência" [1].

Os limites de emissões dos veículos leves foram inicialmente estabelecidos pela Resolução CONAMA n ${ }^{\circ}$ 18/1986, que estabeleceu as Fases L1, L2 e L3. As Fases L4 e L5 foram especificadas pela Resolução CONAMA no 315/2002 [1][2].

Em 2009, o CONAMA aprovou a Resolução ${ }^{\circ}$ 415, que introduziu a Fase L6 que entrou em vigor em 2013. A Fase L6 estabeleceu novos limites para a emissão de escapamento de veículos automotores leves de passageiros e veículos automotores leves comerciais (Tabela 1). [1].

Tabela 1 - Evolução dos Limites de emissões dos veículos leves.

\begin{tabular}{|c|l|}
\hline Fase & \multicolumn{1}{|c|}{ Ano de Exigência } \\
\hline L1 & 1988 \\
\hline L2 & 1992 \\
\hline L3 & 1997 \\
\hline & $2005(40 \%)$ \\
L4 & $2006(70 \%)$ \\
& $2007(100 \%)$ \\
\hline L5 & 2009 \\
\hline & 2013 (Diesel Leve) \\
L6 & 2014 (Otto Novos Modelos) \\
& 2015 (Otto 100\%) \\
\hline
\end{tabular}

Fonte: [2]

Com isso, os limites de emissões de Monóxido de Carbono (CO), Hidrocarbonetos (HC), Óxidos de Nitrogênio (NOx) e Aldeídos Totais (CHO); vêm sofrendo reduções gradativas ao longo dos anos a partir de 1988 com a instauração do PROCONVE. Neste contexto, os aldeídos totais, compostos por Formaldeído e Acetaldeído, tiveram seus limites aceitáveis reduzidos, conforme apresentado na Figura 1. 


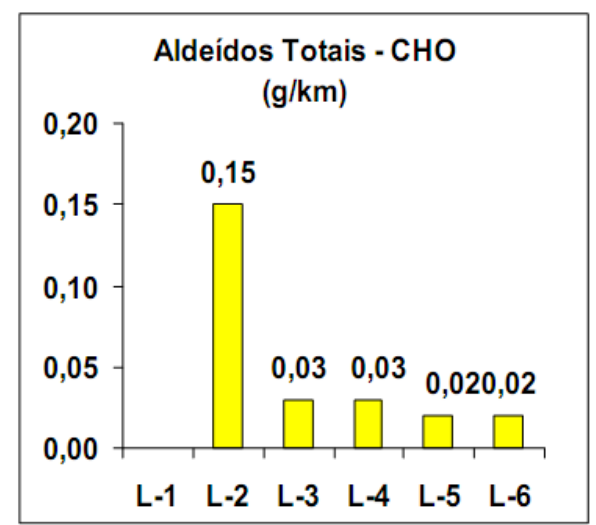

Figura 1 - Limites de emissões de Aldeídos Totais $(\mathrm{g} / \mathrm{km})$ por veículos leves

Fonte:[2]

A coleta e quantificação dos gases regulamentados contidos no gás de escapamento emitidos por veículos rodoviários automotores leves, durante o ciclo de condução desenvolvido em dinamômetro de chassi, são realizados de acordo com a norma ABNT NBR 6601:2012 Veículos rodoviários automotores leves - Determinação de hidrocarbonetos, monóxido de carbono, óxidos de nitrogênio, dióxido de carbono e material particulado no gás de escapamento [7].

O teste é realizado em dinamômetro de chassis, que simula as condições de carga em pista em um trajeto urbano. Durante todo ensaio os gases emitidos são diluídos com ar ambiente, uma fração desses gases é coletada de forma contínua e armazenada em bag's de tedlar para posterior quantificação em bancada analítica específica para cada componente. A configuração básica da sala de ensaios em veículos automotores é apresentada na Figura 2.

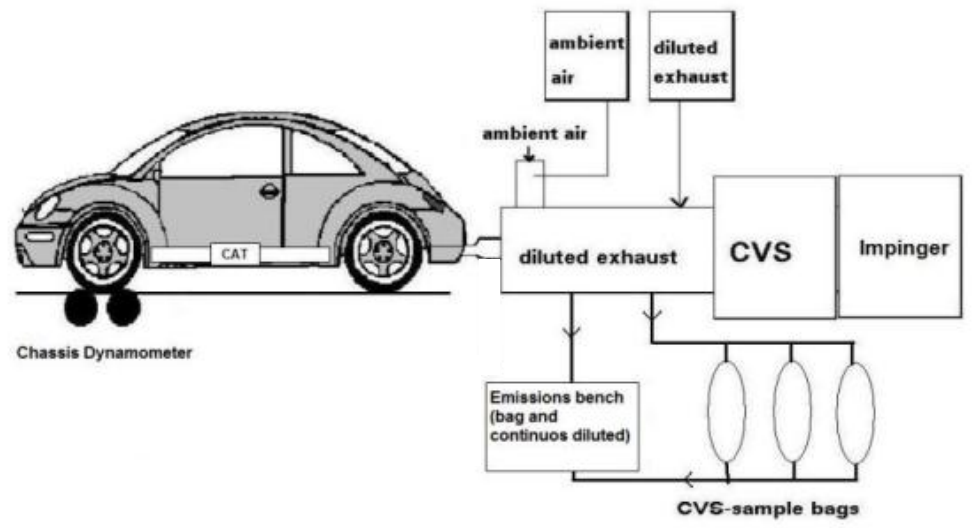

Figura 2 - Modelo esquemático do ensaio de emissões veiculares. Fonte: [3]

O Brasil, através do PROMOT, adotou como padrão de ensaios para motociclos em banco chassis o ciclo de condução em dinamômetro da legislação europeia. Esse ensaio é padronizado pela normativa 97/24/EC, baseando-se na condução do motociclo sobre um dinamômetro de chassis, onde o veículo é fixado com suas rodas propulsoras diretamente ao equipamento, desta forma é possível realizar simulações das cargas de pista, para verificações, ensaios de emissões e engenharia final do produto [9]. Na Figura 3 é apresentada a estrutura de uma sala de ensaios em motociclos. A legislação brasileira não prevê, até o presente momento, limites para emissão de aldeídos nessa classe de veículo automotor. 


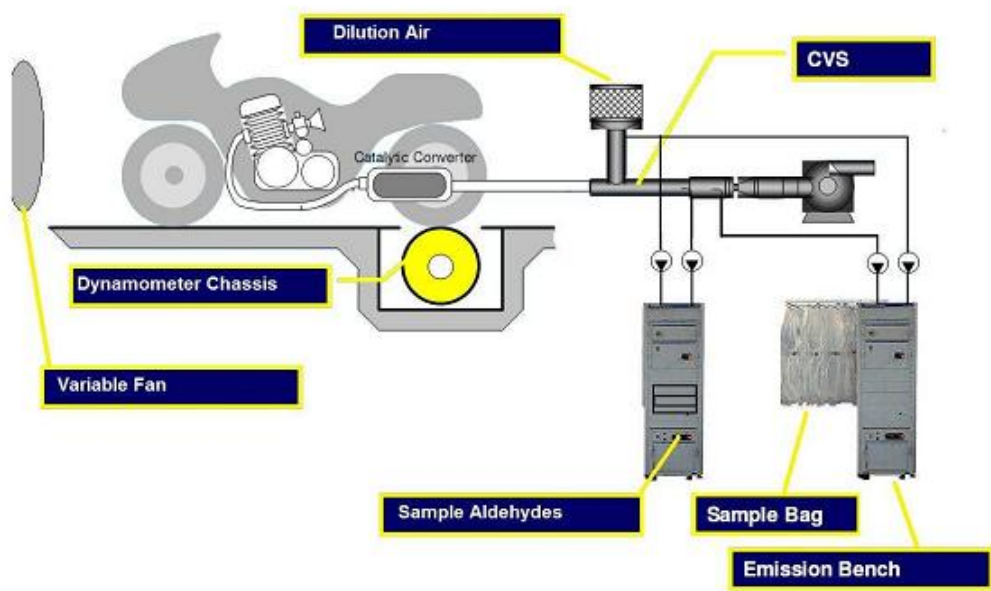

Figura 3 - Configuração de uma sala de ensaios em motociclos.

Fonte: [8]

O teste para medição dos níveis de aldeídos totais provenientes de emissões veiculares é descrito na norma ABNT NBR 12026:2009 - Veículos rodoviários automotores leves Determinação de aldeídos e cetonas contidos no gás de escapamento, por cromatografia líquida - Método DNPH.

As amostras para a determinação dos aldeídos totais são coletadas a partir de uma alíquota do gás de escapamento diluído que é borbulhada em frascos lavadores de gases (Impingers) contendo uma solução absorvente de DNPH (2,4 dinitrofenilidrazina) e Acetonitrila. Estas são coletadas continuamente para cada fase do ciclo (amostra) e também para o ar de diluição (ar ambiente), são utilizados dois impingers, ligados em série, contendo cada um cerca de $25 \mathrm{ml}$ da solução absorvente, conforme a figura 4. Ao final do ensaio o conteúdo de cada par de impingers é transferido para um balão volumétrico, sendo posteriormente avolumado para 100 $\mathrm{ml}$ com Acetonitrila grau HPLC. O modelo é mostrado na Figura 4.

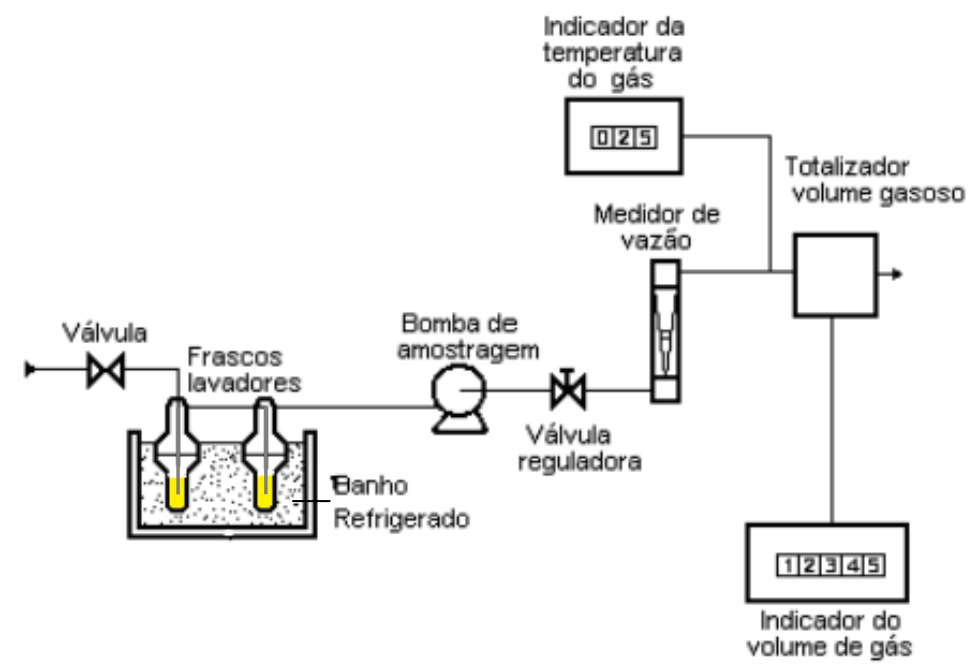

Figura 4 - Representação do processo de amostragem de aldeídos totais em dinamômetro. Fonte: [7]

Portanto, em cada ensaio para determinação da concentração de aldeídos totais presentes em emissões veiculares, são gastos em média $400 \mathrm{~mL}$ de acetonitrila. 
A acetonitrila (CAS $\mathrm{N}^{0}$ 75-05-8), também chamada de cianeto de metila, é um composto orgânico translúcido, inflamável, com temperatura de fusão de $-45^{\circ} \mathrm{C}$ e de ebulição de $81,6^{\circ} \mathrm{C}$. A acetonitrila é miscível em água e em diversos solventes orgânicos, a exemplo de: metanol, acetona, éter etílico, clorofórmio, entre outros [4]. É amplamente empregada em laboratórios de análise química que utilizam a técnica de Cromatografia em fase Líquido de Alta Eficiência (CLAE).

A síntese industrial da acetonitrila é feita a partir da produção preferencial pela amoxidação (processo industrial para a produção de nitrilas utilizando amônia e oxigênio) da acroleína, sendo assim, considerada como subproduto da produção de fibras e resinas de acrílico, produtos de uso predominante na fabricação de automóveis, eletrodomésticos e eletrônicos $[4,5]$.

A oxidação da acroleína na presença de amônia gera a nitrila insaturada correspondente (Equação 1).<smiles></smiles>

Equação 1 - Reação de formação de acrilonitrila.

Fonte: [4]

Existem patentes relacionadas à alteração de processo referente à conversão completa ou quase completa da acroleína em acrilonitrila, no entanto, estes processos geram subprodutos incluindo a acetonitrila (Equação 2).

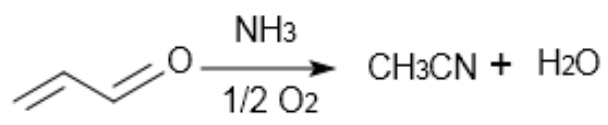

Equação 2 - Reação de formação do subproduto acetonitrila. Fonte: [4]

Nas condições de reação normalmente utilizadas, apenas uma pequena quantidade deste composto é produzida, sendo assim, sua separação é difícil e envolve alto custo.

Em 2008, a disponibilidade de acetonitrila diminuiu no mundo todo, por diferentes razões tais como: redução no consumo de matérias-primas e polímeros usados na indústria automobilística, refletindo assim, na redução da produção de acetonitrila; efeito principal da crise global que reduziu a demanda por produtos a base destas fibras e resinas.

Com isso, a acetonitrila alcançou patamares de $80 \%$ acima de seu preço normal, nesta época de escassez. Devido às características intrínsecas de seu processo de produção, há sempre a possibilidade e o receio de que uma nova alta no seu preço possa ocorrer, devido a retrações mundiais que afetam o mercado de bens de consumo. 
Além das implicações econômicas, existem preocupações relacionadas à exposição à acetonitrila, devido ao seu alto potencial toxicológico. Este solvente é prontamente absorvido quando em contato com o trato gastrointestinal, pele e pulmões, espalhando-se rapidamente pelo corpo. Efeitos sistêmicos em humanos causados pela ingestão deste composto incluem convulsões, náuseas e acidose metabólica. A intoxicação por acetonitrila pode causar graves efeitos sistêmicos devido a sua degradação em cianeto e tiocianato [4,5].

Por esta razão, o desenvolvimento de estudos que promovam a redução do uso de acetonitrila tem grande importância, tanto do ponto de vista ambiental, quanto econômico.

\section{OBJETIVO}

Este trabalho teve por objetivo apresentar uma proposta de modificação na metodologia atualmente existente para a determinação de aldeídos e cetonas, reduzindo o uso do solvente acetonitrila utilizada nos ensaios.

A proposta se baseia na determinação do volume de solução de 2,4-DNPH em acetonitrila de cada fase após o teste, pela técnica de gravimetria; eliminando-se assim a necessidade de se completar o volume do balão volumétrico até a marca de $100 \mathrm{~mL}$. Com essa metodologia é possível uma redução média de $40 \%$ de acetonitrila utilizada em cada ensaio.

\section{METODOLOGIA}

\subsection{ENSAIOS EM MOTOCICLO}

Um motociclo, com motor de 250cc, sistema de injeção flex fuel, equipado com catalisador de três vias, inércia para ensaios $230 \mathrm{~kg}$, foi testado em dinamômetro de chassis no Laboratório de Emissões Veiculares (LEME) do LACTEC, em Curitiba, segundo o ciclo de condução 97/24/EC. O veículo foi abastecido com combustível padrão de emissões A11H50 (combustível contendo 50\% de gasolina A22 e 50\% de etanol hidratado de referência) e as demais condições de ensaio foram mantidas durante os testes. Conforme citado anteriormente, essa classe de veículo automotor não possuí, até o presente momento, regulamentação para as emissões de aldeídos.

\subsection{ENSAIOS EM VEÍCULO LEVE DE PASSAGEIROS}

O veículo utilizado foi um automóvel leve de passageiros, do ciclo Otto, com as seguintes características: potência de $115 \mathrm{CV}$; torque: $157 \mathrm{Nm}$ a $3750 \mathrm{rpm}$, motor 1.6 litros, 16 válvulas; massa de inércia de $1474 \mathrm{~kg}$; ano de fabricação 2009; $19.000 \mathrm{~km}$ no início do programa de testes, sistema de injeção eletrônica EFI; Flex Fuel; conversor catalítico de três vias, acoplado em circuito fechado. Os testes foram realizados em dinamômetro de chassis de 48" de acordo com o ciclo de condução FTP 75 e a norma brasileira NBR6601[7]. Emissões regulamentadas (CO, HC e NOx) foram medidas com bancadas Horiba série 7000. Os aldeídos foram determinados pela técnica de Cromatografia Líquida de Alta Desempenho (HPLC) de acordo com a norma brasileira NBR12026 [6]. 


\subsection{METODOLOGIA PROPOSTA PARA REDUÇÃO DO USO DE ACETONITRILA EM ENSAIOS DE DETERMINAÇÃO DE ALDEÍDOS TOTAIS}

A proposta apresentada para modificação da metodologia de preparo de amostra para análise de aldeídos totais, provenientes de emissões de veículos automotores e motociclos, tem as premissas de ser rápida e de manter a mesma qualidade e precisão de resultados quando comparada à metodologia atualmente empregada.

Inicialmente foram realizados testes para determinar experimentalmente a densidade do solvente acetonitrila, da marca usualmente utilizada nos ensaios, para verificar quanto este valor diferia do valor fornecido pelo fabricante. Por meio de testes de determinação de densidade, foi possível notar que a diferença entre o valor obtido em laboratório e o citado na embalagem do produto não era significativa. Desta forma o valor fornecido foi utilizado para todos os cálculos onde a densidade da solução de acetonitrila fosse necessária.

Os balões utilizados foram previamente pesados em balança analítica (com precisão de $0,0001 \mathrm{~g}$ ). Após todo o processo de testes no veículo e coleta de amostras de gases nos impingers, todo o volume de solução absorvedora contida em ambos os frascos foi transferido para os balões com massas conhecidas.

Novamente os balões foram pesados e então, por diferença de massas, foi determinada a massa de solução contida no recipiente. Assim, utilizando-se como base o valor da densidade fornecido pelo fabricante da acetonitrila, foi possível calcular o volume de solução por meio da aplicação da equação que determina que a Densidade é diretamente proporcional a massa e inversamente proporcional ao volume $(\mathrm{d}=\mathrm{m} / \mathrm{V})$.

Com o volume da amostra determinado, este foi substituído nas equações onde usualmente é utilizado o valor $100 \mathrm{~mL}$, tanto para o cálculo de concentração em $\mathrm{mg} / \mathrm{L}$ de formaldeído e acetaldeído como nos cálculos de g/km emitidos pelo veículo em teste.

Para efeito comparativo, na Figura 5 está representada a sequência de etapas das metodologias. 


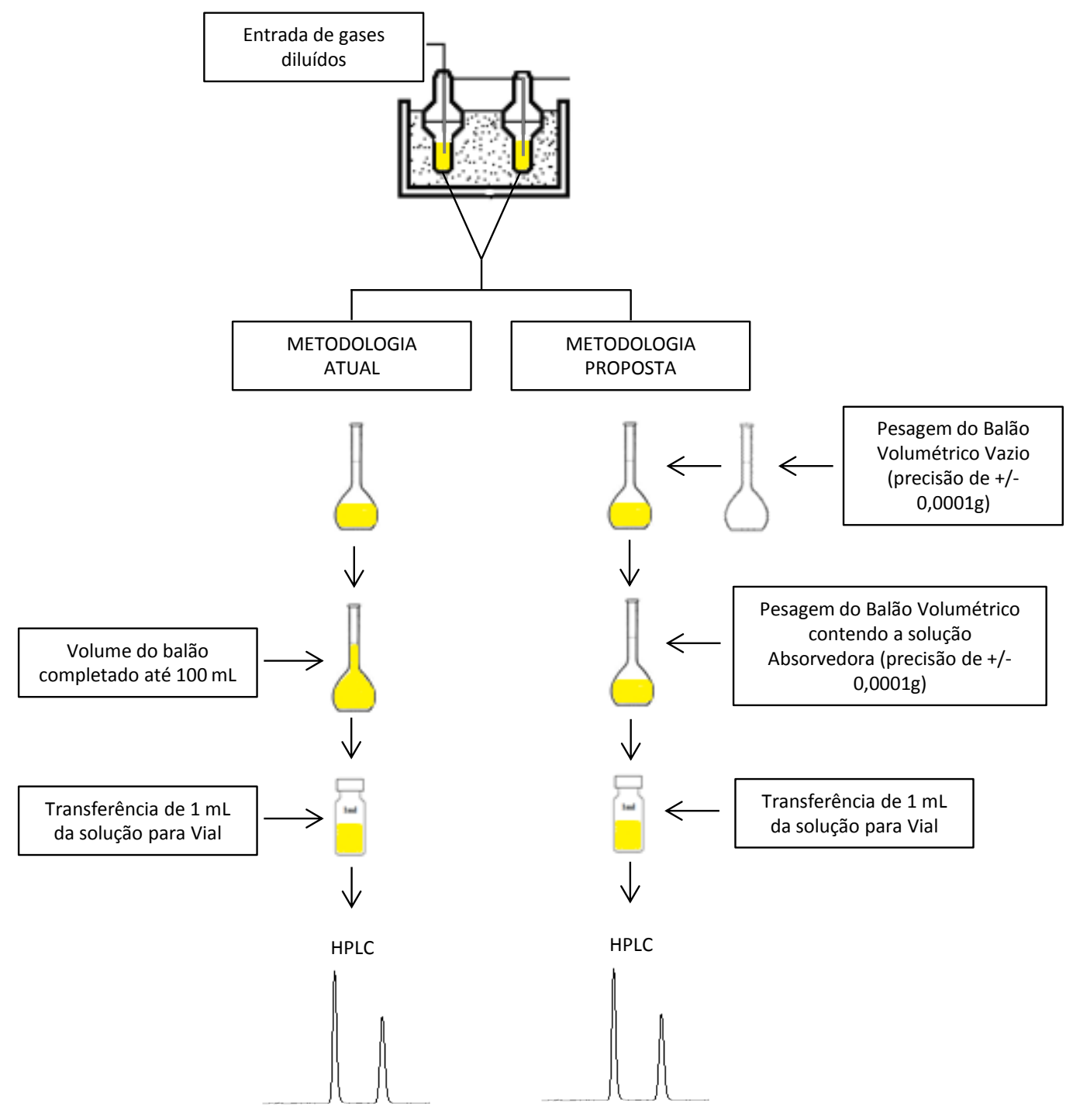

Figura 5 - Comparação das metodologias para de preparo de amostra para determinação de aldeídos totais.

Fonte: Os autores.

Entretanto, para avaliação comparativa do resultado de forma eficiente, e validação da metodologia proposta, foi preciso realizar a análise cromatográfica de uma mesma amostra (ensaio). Para isso, após o teste em dinamômetro, as soluções contidas nos impingers referentes a cada fase foram transferidos para um balão volumétrico de $100 \mathrm{~mL}$ previamente pesado. Em seguida, foi retirada uma amostra de $1 \mathrm{~mL}$ desta solução e realizada a análise por cromatografia. A concentração de aldeídos totais foi determinada com base no volume contido no balão. Na sequência, o volume do balão volumétrico foi completado com acetonitrila até a marca de $100 \mathrm{~mL}$, e novamente uma amostra foi retirada e analisada por cromatografia. Assim, os resultados obtidos nas duas etapas foram comparados. O método de comparação de resultados é mostrado na Figura 6. 


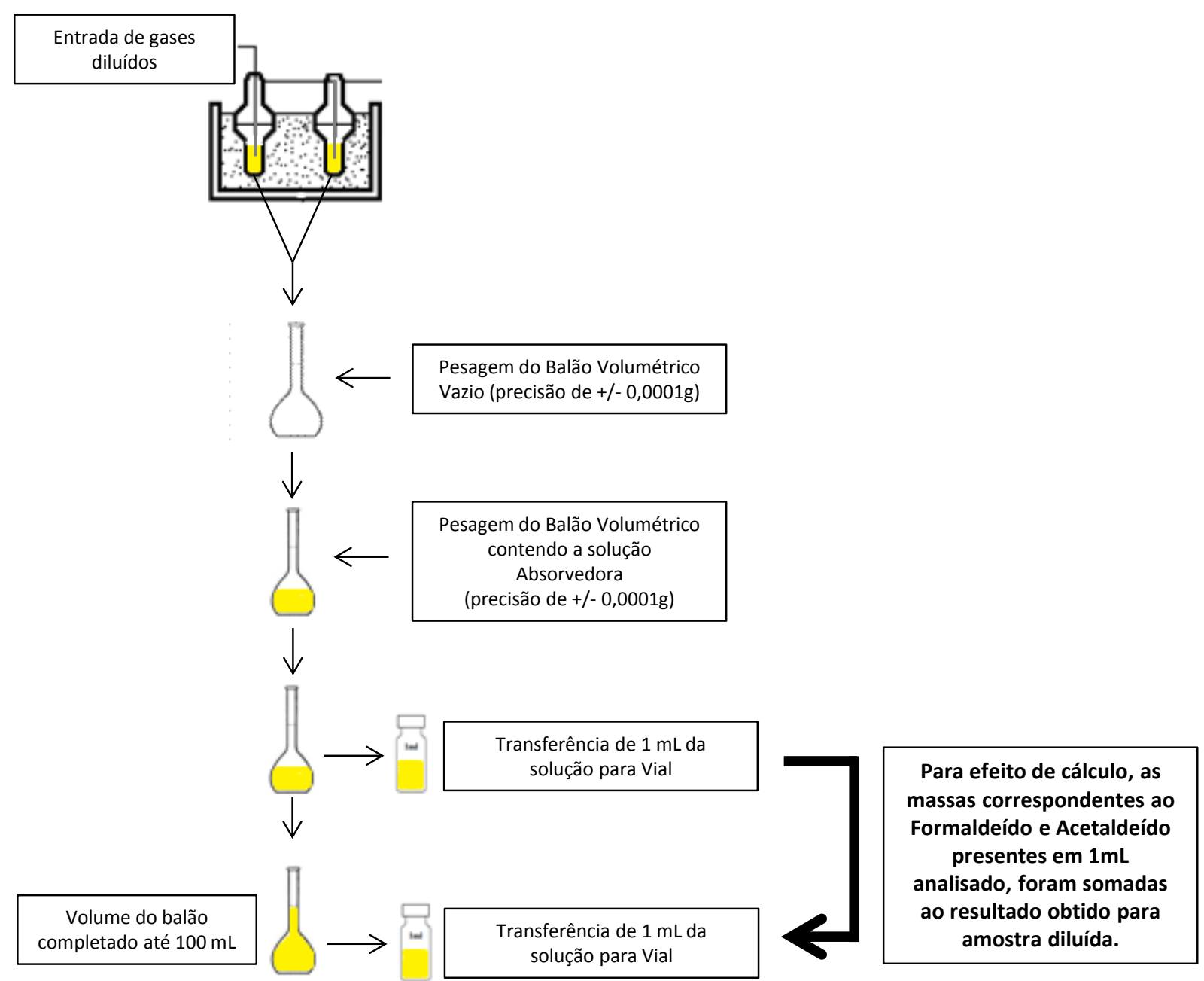

Figura 6 - Processo de validação da alteração de metodologia proposta.

Fonte: Os autores.

\section{RESULTADOS E DISCUSSÃO}

\subsection{DETERMINAÇÃO DA DENSIDADE DA ACETONITRILA}

Uma vez que a proposta de alteração de metodologia para preparo de amostras para análise de aldeídos preconiza a inclusão/substituição de etapas, foi adotada a premissa de se utilizar o valor de densidade da acetonitrila fornecida pelo próprio fabricante, de modo a simplificar a execução do ensaio.

Entretanto para que o valor nominal pudesse ser utilizado de forma eficiente, testes em laboratório foram realizados para comparar o valor teórico fornecido pelo principal fabricante deste solvente, com o obtido experimentalmente. Os resultados obtidos demonstraram que o valor de densidade informado poderia ser utilizado sem restrições. $\mathrm{O}$ valor de referência utilizado nesta pesquisa foi de $0,786 \mathrm{~g} / \mathrm{mL}$. 
O valor da densidade é importante para a determinação do volume final de solução absorvente contida nos impingers, pois, apesar de estes serem preenchidos inicialmente com $25 \mathrm{~mL}$ de solução em cada frasco lavador de gás, há um acréscimo neste volume proveniente de sua limpeza, o que gera uma faixa que varia normalmente entre $55 \mathrm{~mL}$ a $70 \mathrm{~mL}$.

\subsection{ENSAIOS EM MOTOCICLOS E VEICULOS.}

Para cada teste realizado em motociclos e veículos, foram gerados os resultados de concentração de aldeídos (formaldeído e acetaldeído) em g/km. A determinação da concentração foi realizada por cromatografia em fase líquida.

Os testes de comparação de resultados entre ambas as metodologias: atual (volumétrica) e proposta (gravimétrica) foram realizados conforme modelo esquemático mostrado na Figura 6. A metodologia descrita como "Volumétrica Corrigida" expressa os valores corrigidos matematicamente para inclusão da massa de aldeídos presente na amostra retirada para ensaio cromatográfico da amostra do teste gravimétrico. Este valor servirá como base para comparação dos resultados obtidos pelas diferentes metodologias.

Os resultados obtidos para estes ensaios são mostrados nas Tabelas 2-7.

Tabela 2 - Comparação de concentração $(\mathrm{g} / \mathrm{km})$ de aldeídos obtidos no teste $1 \mathrm{com}$ motociclos.

\begin{tabular}{|c|c|c|}
\hline \multirow{2}{*}{ Metodologia } & \multicolumn{2}{|c|}{ Concentração de aldeídos } \\
\cline { 2 - 3 } & Formaldeído $(\mathrm{g} / \mathrm{km})$ & Acetaldeído $(\mathrm{g} / \mathrm{km})$ \\
\hline Volumétrica & 0,00153 & 0,01030 \\
\hline Gravimétrica & 0,00156 & 0,01057 \\
\hline Volumétrica Corrigida & 0,00155 & 0,01043 \\
\hline
\end{tabular}

Tabela 3 - Comparação de concentração $(\mathrm{g} / \mathrm{km})$ de aldeídos obtidos no teste $2 \mathrm{com}$ motociclos.

\begin{tabular}{|c|c|c|}
\hline \multirow{2}{*}{ Metodologia } & \multicolumn{2}{|c|}{ Concentração de aldeídos } \\
\cline { 2 - 3 } & Formaldeído $(\mathrm{g} / \mathrm{km})$ & Acetaldeído $(\mathrm{g} / \mathrm{km})$ \\
\hline Volumétrica & 0,00124 & 0,00930 \\
\hline Gravimétrica & 0,00125 & 0,00952 \\
\hline Volumétrica Corrigida & 0,00125 & 0,00940 \\
\hline
\end{tabular}

Tabela 4 - Comparação de concentração $(\mathrm{g} / \mathrm{km})$ de aldeídos obtidos no teste $3 \mathrm{com}$ motociclos.

\begin{tabular}{|c|c|c|}
\hline \multirow{2}{*}{ Metodologia } & \multicolumn{2}{|c|}{ Concentração de aldeídos } \\
\cline { 2 - 3 } & Formaldeído $(\mathrm{g} / \mathrm{km})$ & Acetaldeído $(\mathrm{g} / \mathrm{km})$ \\
\hline Volumétrica & 0,00126 & 0,00887 \\
\hline Gravimétrica & 0,00120 & 0,00911 \\
\hline Volumétrica Corrigida & 0,00128 & 0,01026 \\
\hline
\end{tabular}


Tabela 5 - Comparação de concentração $(\mathrm{g} / \mathrm{km})$ de aldeídos obtidos no teste 1 com veículos.

\begin{tabular}{|c|c|c|}
\hline \multirow{2}{*}{ Metodologia } & \multicolumn{2}{|c|}{ Concentração de aldeídos } \\
\cline { 2 - 3 } & Formaldeído $(\mathrm{g} / \mathrm{km})$ & Acetaldeído $(\mathrm{g} / \mathrm{km})$ \\
\hline Volumétrica & 0,00141 & 0,01160 \\
\hline Gravimétrica & 0,00154 & 0,01229 \\
\hline Volumétrica Corrigida & 0,00143 & 0,01175 \\
\hline
\end{tabular}

Tabela 6 - Comparação de concentração $(\mathrm{g} / \mathrm{km})$ de aldeídos obtidos no teste 2 com veículos.

\begin{tabular}{|c|c|c|}
\hline \multirow{2}{*}{ Metodologia } & \multicolumn{2}{|c|}{ Concentração de aldeídos } \\
\cline { 2 - 3 } & Formaldeído $(\mathrm{g} / \mathrm{km})$ & Acetaldeído $(\mathrm{g} / \mathrm{km})$ \\
\hline Volumétrica & 0,00147 & 0,01026 \\
\hline Gravimétrica & 0,00153 & 0,01043 \\
\hline Volumétrica Corrigida & 0,00149 & 0,01038 \\
\hline
\end{tabular}

Tabela 7 - Comparação de concentração $(\mathrm{g} / \mathrm{km})$ de aldeídos obtidos no teste 3 com veículos.

\begin{tabular}{|c|c|c|}
\hline \multirow{2}{*}{ Metodologia } & \multicolumn{2}{|c|}{ Concentração de aldeídos } \\
\cline { 2 - 3 } & Formaldeído $(\mathrm{g} / \mathrm{km})$ & Acetaldeído $(\mathrm{g} / \mathrm{km})$ \\
\hline Volumétrica & 0,00122 & 0,00820 \\
\hline Gravimétrica & 0,00124 & 0,00842 \\
\hline Volumétrica Corrigida & 0,00123 & 0,00829 \\
\hline
\end{tabular}

A massa de aldeídos totais em $\mathrm{g} / \mathrm{km}$ foi determinada pela aplicação dos dados coletados durante o ciclo de ensaio dinamométrico. Assim, para efeito comparativo, os resultados de aldeídos totais determinados pelas duas metodologias, atual (volumétrica) e proposta (gravimétrica), foram agrupados. A correlação de resultados foi determinada considerando-se como valor base, a concentração de aldeídos obtida pela metodologia atualmente empregada. Os resultados constam nas tabelas 8-13.

Tabela 8 - Correlação da concentração de aldeídos totais $(\mathrm{g} / \mathrm{km})$ obtidos no teste $1 \mathrm{com}$ motociclos.

\begin{tabular}{|c|c|c|}
\hline Metodologia & Aldeídos Totais $(\mathrm{g} / \mathrm{km})$ & Correlação \\
\cline { 1 - 2 } Volumétrica & 0,01198 & \multirow{2}{*}{$98,8 \%$} \\
\hline Gravimétrica & 0,01213 & \\
\hline
\end{tabular}

Tabela 9 - Correlação da concentração de aldeídos totais $(\mathrm{g} / \mathrm{km})$ obtidos no teste 2 com motociclos.

\begin{tabular}{|c|c|c|}
\hline Metodologia & Aldeídos Totais $(\mathrm{g} / \mathrm{km})$ & Correlação \\
\hline Volumétrica & 0,01065 & $98,9 \%$ \\
\hline Gravimétrica & 0,01077 & \\
\hline
\end{tabular}


Tabela 10 - Correlação da concentração de aldeídos totais $(\mathrm{g} / \mathrm{km})$ obtidos no teste 3 com motociclos.

\begin{tabular}{|c|c|c|}
\hline Metodologia & Aldeídos Totais $(\mathrm{g} / \mathrm{km})$ & Correlação \\
\hline Volumétrica & 0,01154 & \multirow{2}{*}{$89,34 \%$} \\
\hline Gravimétrica & 0,01031 & \\
\hline
\end{tabular}

Tabela 11 - Correlação da concentração de aldeídos totais $(\mathrm{g} / \mathrm{km})$ obtidos no teste $1 \mathrm{com}$ veículos.

\begin{tabular}{|c|c|c|}
\hline Metodologia & Aldeídos Totais $(\mathrm{g} / \mathrm{km})$ & Correlação \\
\hline Volumétrica & 0,01318 & $95,3 \%$ \\
\hline Gravimétrica & 0,01383 & \\
\hline
\end{tabular}

Tabela 12 - Correlação da concentração de aldeídos totais $(\mathrm{g} / \mathrm{km})$ obtidos no teste $2 \mathrm{com}$ veículos.

\begin{tabular}{|c|c|c|}
\hline Metodologia & Aldeídos Totais $(\mathrm{g} / \mathrm{km})$ & Correlação \\
\hline Volumétrica & 0,01187 & $99,2 \%$ \\
\hline Gravimétrica & 0,01196 & \\
\hline
\end{tabular}

Tabela 13 - Correlação da concentração de aldeídos totais $(\mathrm{g} / \mathrm{km})$ obtidos no teste $3 \mathrm{com}$ veículos.

\begin{tabular}{|c|c|c|}
\hline Metodologia & Aldeídos Totais $(\mathrm{g} / \mathrm{km})$ & Correlação \\
\hline Volumétrica & 0,00952 & $98,6 \%$ \\
\hline Gravimétrica & 0,00966 & \\
\hline
\end{tabular}

Os resultados apresentados mostraram uma grande correlação entre as duas técnicas apresentadas. Assim, a metodologia proposta para preparo das amostras para ensaios de aldeídos é interessante tanto do ponto de vista econômico, quanto ambiental, pois, promove a redução de aproximadamente $40 \%$ do volume de acetonitrila utilizado em laboratórios de emissões veiculares. 


\section{CONCLUSÃO}

Esta pesquisa teve por objetivo, apontar uma alternativa para redução do uso de acetonitrila em ensaios de determinação da concentração de aldeídos provenientes de emissões de veículos automotores e motociclos. Foram obtidos resultados que comprovaram a eficiência da alteração na metodologia atualmente empregada, a qual é baseada em medições volumétricas, passando-se a realizar medidas gravimétricas para determinação do volume de solução absorvedora contida nos impingers após os testes de emissões de aldeídos.

Foi atingido um valor de $99,2 \%$ de correlação entre a atual metodologia e a proposta; no universo de 3 em ensaios realizados em veículos. Da mesma forma, após 3 testes realizados em motociclos, este valor alcançou o nível de 98,9\%. Estes valores foram considerados satisfatórios, no entanto, entende-se que novos testes precisam ser realizados para comprovação da metodologia proposta.

Os níveis preliminares de correlação entre os métodos citados neste trabalho, indicam um grande potencial de aplicação da metodologia proposta, para a redução de aproximadamente $40 \%$ no uso do solvente acetonitrila utilizado nos testes de determinação de concentração de aldeídos em emissões veiculares. Esta redução gera reflexos não somente do ponto de vista econômico, mas também no aspecto ambiental.

Como continuidade dos trabalhos, sugere-se a intercomparação de resultados por meio da amostragem dupla de aldeídos, sendo a primeira no sistema convencional, e em paralelo, a coleta por meio do sistema de álcool não queimado. Desta forma, novas evidências da eficiência da metodologia proposta podem ser avaliadas.

\section{REFERÊNCIAS}

[1] PROCONVE: Programa de Controle de Poluição do Ar por Veículos Automotores Resumo Proconve atualizado em 11/2013. Disponível em http://www.mma.gov.br - Acesso em 20/05/2014.

[2] JOSEPH JR., Henry. PROCONVE: As Fases Passadas e Futuras - Seminário sobre emissões de veículos diesel, São Paulo/SP, 2009. Disponível em http://www.anfavea.com.br/documentos/SeminarioItem1.pdf - Acesso em 17/05/2014.

[3] SILVA, Katia Cristine da Costa; DAEMME, Luiz Carlos; PENTEADO, Renato; MACEDO, Valéria de Cássia; CORREA, Sérgio Machado. Emissões de álcool não queimado e poluentes legislados de veículo leve com gasolina A22, A85 e EHR. Blucher Engineering Proceedings, vol. 1, núm. 1, 2014.

[4] BRACHT, Fabrício. Métodos de preparação industrial de solventes e reagentes químicos. Revista Virtual de Química ISSN 1984-6835, vol. 3, núm. 1, 51-52. Disponível em http://www.uff.br/rvg - Acesso em 19/05/2014. 
[5] CASSINI, Sérvio Túlio Alves; ANTUNES, Paulo Wagner Pereira; KELLER, Regina. Validação de método analítico livre de acetonitrila para análise de microcistinas por cromatografia líquida de alta eficiência. Química Nova, vol. 36, núm. 8, 1208-1213, 2013.

[6] ABNT NBR 12026: Veículos rodoviários automotores leves - Determinação de aldeídos e cetonas contidos no gás de escapamento, por cromatografia líquida - Método DNPH, 2009.

[7] ABNT. NBR 6601: Determinação de hidrocarbonetos, monóxido de carbono, óxidos de nitrogênio, dióxido de carbono e material particulado no gás de escapamento, 2012.

[8] DAEMME, Luiz Carlos; PENTEADO, Renato; ZOTIN, Fátima M. Z. Emissão de Aldeídos em motociclo Flex Fuel, abastecido com combustíveis E22, E61 e E100. Simpósio Internacional de Engenharia Automotiva - Simea 2012. 